protection and profit earning as well as sustainability, considering the effectiveness, utility and benefits of those policies. The situation in big firms is rather acceptable but small and medium sized enterprises and informal sector need more effort. Globally, around 4\% of GDP is lost due to the costs of work related injuries and illness with global financial losses exceeding $\$ 1250$ billion. This cost is high compared with that of cancer or AIDS. The burden of occupational injuries and illness is also high when calculating Disability-Adjusted Life Years lost, or healthy years of life lost either from disability or premature death. This will hinder economic development and sustainability. So, all should be motivated towards cost effectiveness OHS programmes as a priority in their agenda. Occupational health literacy, unemployment, workers' behaviour, high risk group workers (children, women, and elderly and immigrants workers), inequity and inequality should be considered in OHS programmes. Society, workers, payers, and providers' perspectives must be investigated in facing challenges towards OHS and sustainability. Reallocation of resources, controlling of externalities, enforcement of regulations and encouraging of innovation are crucial elements for sustainable development and economic growth.

\section{OCCUPATIONAL SAFETY AND HEALTH IN AFRICA: STATE OF THE ART AND FUTURE CHALLENGES}

Barbra C Khayongo*. Ministry of Gender, Labour and Social Development, Kampala, Uganda

\subsection{6/oemed-2018-ICOHabstracts.854}

Aim of special session This special session provides a forum for African Countries to show case, and share experiences on progress made in occupational safety and health in Africa. It presents an opportunity for Safety and Health practitioners to share research findings, practical skills and knowledge on best practices of how to address safety and health challenges and thus advance the safety and health culture for development.

Co-chair of Special Session:Diana Gagliardi

\section{$1643 a$ OCCUPATIONAL PHYSICAL INJURIES AMONG WORKERS IN ONSHORE OIL DRILLING OPERATIONS IN TURKANA COUNTY, KENYA}

CO Kamol. Kenyatta University, Nairobi, Kenya

\subsection{6/oemed-2018-ICOHabstracts.855}

Introduction Onshore oil drilling involves use of heavy machinery and tools which contribute to occupational injuries. Onshore oil drilling attracts workers that operate in isolated locations coupled with harsh environmental conditions. Such conditions influence occupational hazards, that give rise to occupational injuries. The study sought to assess occupational physical injuries among workers in onshore oil drilling operations in Turkana County, Kenya.

Methods A cross-sectional descriptive study was conducted among 164 workers from October 2015 to February 2016. Convenience sampling and systematic random sampling were used to select study participants. Data were collected through pre-tested semi-structured questionnaires. Data collected were analysed using SPSS version 20. Multivariate logistic regression analysis was used to assess the relative effect of independent variables on the outcome variable. The level of significance was set at $p<0.05$.

Results $9.8 \%$ of workers experienced physical injuries. Duration worked in oil drilling industry $\left(\chi^{2}=11.557, d f=4\right.$ $p=0.021)$, level of education $\left(\chi^{2}=8.273, d f=3 p=0.016\right)$, hazard awareness $\left(\chi^{2}=3.655, d f=1 \quad p=0.056\right)$, worker awareness of activities at work that pose risks of injuries $\left(\chi^{2}=7.697\right.$, $d f=1 p=0.006)$, awareness of occupational health and safety legal frameworks $\left(\chi^{2}=7.87, d f=1 p=0.005\right)$, worker participation in fire drills $\left(\chi^{2}=3.724, d f=1 p=0.054\right)$ and on job training $\left(\chi^{2}=1.359, d f=1 \quad p=0.038\right)$ were associated with occurrence of physical injuries at bivariate analysis. Age (AOR $=0.354, p=0.014,95 \% \mathrm{CI}: 0.154$ to 0.811 ) and issues experienced while using Personal Protective Equipment $(\mathrm{AOR}=3.652, p=0.053,95 \% \mathrm{CI}: 0.984$ to 13.553$)$ were significant predictors to occupational physical injuries at logistic regression.

Conclusion There is a clear interplay between risk factors; socio-demographic factors, environmental factors, and behavioural factors with occurrence of physical injuries. This information could be tapped to formulate occupational health and safety specific intervention strategies for oil and gas industry.

\section{3b WHENCE OCCUPATIONAL HEALTH SERVICES IN SOUTH AFRICA?}

TM Balfour. Chamber of Mines of South Africa, Johannesburg, South Africa

\subsection{6/oemed-2018-ICOHabstracts.856}

Abstract South Africa has a population of 55 million people, with 10 million employed in the formal sector, and around 3 million in the informal sector. Occupational health services are important for a working population and these are available unevenly in the country, being more developed in the private sector and poorly developed in the public sector. The country has published a White Paper and a Policy on universal health coverage, in the form of the National Health Insurance (NHI). Occupational health services are part of the package of primary health care services that the NHI will offer. This presentation will explore the possible models for the delivery of occupational health services under an NHI. A literate review of models of funding and delivery of occupational health services in developed (Australia, Canada and UK) and developing (Brazil, Chile and Zambia) countries was conducted. Interviews with experts in occupational health were also conducted. The models of provision in developed countries, with universal health coverage and private sector participation are contrasted with the models in developing countries like Zambia where the services are government-led and delivered. The key challenge was finding models for South Africa that lead to greater equity in service delivery across the private and public sectors. The introduction of the NHI in South Africa will lead to new models of delivery of occupational health services. An opportunity exists to bridge the current inequalities between the public and private health sectors and improve access to occupational health services for all workers. 